\title{
Comparison of the sensitivity of coprological methods in detecting Anoplocephala perfoliata invasions
}

\author{
Krzysztof Tomezuk • Krzysztof Kostro • \\ Klaudiusz Oktawian Szczepaniak • Maciej Grzybek • \\ Maria Studzińska • Marta Demkowska-Kutrzepa • \\ Monika Roczeń-Karczmarz
}

Received: 19 December 2013 / Accepted: 11 April 2014 / Published online: 29 April 2014

(C) The Author(s) 2014. This article is published with open access at Springerlink.com

\begin{abstract}
The autopsy of 487 slaughter horses revealed the presence of Anoplocephala perfoliata in 36 animals. The invasions varied in the intensity (3 to 2,069 tapeworms) and in the level of tapeworms' proglottid maturity. Twenty nine horses were found to contain tapeworms with gravid proglottid. Fecal samples collected from the rectum were tested using following techniques: flotation with solution-saturated $\mathrm{NaCl}$, decantation, McMaster's, and modified sedimentationflotation methods $(50 \mathrm{~g}$ feces samples, flotation solutionsaturated $\mathrm{NaCl}$ and sucrose, specific gravity $1.25 \mathrm{~g} / \mathrm{ml}$ ). The number of $A$. perfoliata positive fecal samples was significantly higher using the sedimentation-flotation methods 21 $(58.33 \%)$ than flotation $6(16.66 \%)$, decantation $3(8.33 \%)$, and McMaster's 1 (2.77\%) techniques. The sensitivities of the coprological methods during the patent period were 20.69, $10.34,3.45$, and $72.41 \%$ for the flotation, decantation, McMaster's, and sedimentation-flotation method, respectively. Sedimentation-flotation techniques proved to be more sensitive than other one. The lowest intensity of invasion possible to detect using this method was nine tapeworms with gravid proglottid.
\end{abstract}

Keywords Anoplocephala perfoliata · Gravid proglottid · Coprological methods $\cdot$ Sensitivity

\section{Introduction}

For many years, equine anoplocephalosis has been considered to be incidental finding in the intestinal tracts of horses at post

K. Tomczuk $(\bowtie) \cdot$ K. Kostro $\cdot$ K. O. Szczepaniak $\cdot$ M. Grzybek $\cdot$

M. Studzińska $\cdot$ M. Demkowska-Kutrzepa $\cdot$ M. Roczeń-Karczmarz

University of Life Sciences in Lublin, Lublin, Poland

e-mail: krzysztof.tomczuk@up.lublin.pl mortem examination and rarely associated with clinical disease. However, nowadays, it is an emerging problem for both breeders and veterinary surgeons (Gundlach et al. 2004; Kornaś et al. 2007, 2010; Rehbein et al. 2013). Anoplocephala perfoliata belongs to the family of Anoplocephalidae (Cyclophyllidea, Cestoda) and has an indirect life cycle via pasture dwelling oribatid mites from Oribatidae spp. The tapeworm infestation in equines results from pasture invasion. Mites containing infective cysticercoids of the parasite are ingested by grazing horses. The parasite attaches to the intestinal mucosa of the ileocaecal junction with the suckers on the scolex. It matures to an adult in 6-10 weeks and attains the size of only $5-8 \mathrm{~cm}$ in length. Adult parasites shed gravid proglottids that break up during passage through the horse's large intestine (Deplazes et al. 2013; Schnieder 2006).

Several authors have widely described pathology of this invasion including type of distribution (clustered or dispersed) and pathology. Mucosal ulceration, submucosal oedema, hypertrophy of the distal ileum, and decreased ileocaecal valve distensibility have all been reported to occur at the site of parasite attachment, and the severity of pathology is directly proportional to parasite infection intensity (Pavone et al. 2011; De Almeida et al. 2008). The mechanisms by which this pathology arises remain unexplored, but it would seem reasonable to consider both mechanical obstruction and parasitederived antigens in these processes. The infected animals usually demonstrate a good nutrition status although several clinical conditions have been associated with $A$. perfoliata infections in horses (Deplazes et al. 2013). Periodic paroxysmal colics, reduced stress, intussusception, and cecal rupture conditions of the animals can be the only evident symptoms suggesting infestation (Barclay et al. 1982; Proudman and Trees 1999; Proudman and Holdstock 2000; Ryu et al. 2001).

Recent studies have reported prevalence of $A$. perfoliata in different countries, pointing to this species as the most 
common equine tapeworm. Its prevalence varies between 6 and $100 \%$ (Trotz-Williams et al. 2008; Michela et al. 2009; Sangioni et al. 2009; Pavone et al. 2011; Hinney et al. 2011) In Poland, its prevalence varies from 0 to even $72 \%$ depending on type of breeding system and geographical region (Ślivińska et al. 2009; Tomczuk 2012).

Despite the high prevalence of $A$. perfoliata, there is no best method to detect tapeworm infection in horses. Macroscopic methods of fecal analysis are rarely applied because of small size of segments and their irregular excretion. Detached proglottids are usually without eggs and morphologically do not resemble the classical segments of tapeworm (Schuster 1991; Ślivińska et al. 2009). Microscopic fecal analyses have limitations for detecting tapeworms due to a low concentration of eggs in feces (Slocombe 2006).

Coprological methods like flotation and sedimentation used routinely for the detection of carnivores' cestodosis are often unreliable. The McMaster technique has also a very low sensitivity for anoplocephalosis (Proudman and Edwards 1992; Nilsson et al. 1995; Meana et al. 1998; Williamson et al. 1998). The most recommended coprological method is a sedimentation-flotation technique with sensitivity estimated above $50 \%$ (Gundlach et al. 2003; Williamson et al. 1998). PCR and ELISA tests compared to standard coprological methods are more sensitive but procedures are time- and cost- consuming and also restricted to specialist laboratories (Traversa et al. 2008). What is more, relatively long and variable prepatent period of invasion impacts the diagnostics as well. High tapeworm burdens usually increase the sensitivity of coprological methods (Proudman and Edwards 1992; Williamson et al. 1998). However, previous studies have shown poor correlation between infection intensity and sensitivity of coprological methods used routinely for the detection of A. perfoliata (Gundlach et al. 2003; Gawor 1995). This has possible association with tapeworm maturity and the number of gravid proglottids. Therefore, the aim of this study was to prove the sensitivity of standard coproscopic methods and a modified sedimentation-flotation method on the basis of postmortem examinations confirming the prevalence of A. perfoliata and the stage of tapeworms' maturity.

\section{Materials and methods}

Parasitological post-mortem examinations of gastrointestinal tracts of 487 slaughtered horses were performed to diagnose the intensity of tapeworm invasion between August and November 2010. Species identification and maturity stages of tapeworms were determined considering morphological characteristics and the presence of eggs in the gravid segments (Schuster 1991). For each positive horse (tapeworms present in the cecum), fecal samples were collected from the rectum or small colon for coproscopic examinations. Samples were analyzed by the conventional coproscopical methods (Gundlach et al. 2003; Schnieder 2006).

Four methods were applied: flotation $(F)$ (flotation solution-saturated sodium chloride; specific gravity $1.2 \mathrm{~g} /$ $\mathrm{mL})$, sedimentation $(\mathrm{Sed})$, modified sedimentation-flotation $(\operatorname{Sed}-F)$, and McMaster $(M c M)$ technique. Fecal samples for each method weighed $5 \mathrm{~g}$ flotation and decantation method, $50 \mathrm{~g}$ modified sedimentation-flotation techniques, $2 \mathrm{~g}$ McMaster technique.

The modified sedimentation-flotation technique involved a $50 \mathrm{~g}$ fecal sample poured over with $0.0025 \%$ Tween 80 solution in $400 \mathrm{~mL}$ beakers, homogenized for $60 \mathrm{~s}$ and allowed to stand for $30 \mathrm{~min}$. The suspension was filtered through a $200-\mu \mathrm{m}$ sieve to high-capacity centrifuge tubes. The filtrate was centrifuged at $2,600 \mathrm{~g}$ for $10 \mathrm{~min}$. After supernatant removing, glass beads and a saturated solution of $\mathrm{NaCl}$ and sucrose (specific gravity $1.25 \mathrm{~g} / \mathrm{mL}$ ) were added to the precipitate. The suspension was homogenized and transferred (after filtration of bead) to a 100-mL tube. Samples were centrifuged at 2,600 g for $2 \mathrm{~min}$. The flotation solution was supplemented to the formation of a convex meniscus. Tubes were covered with cover glasses. After a 30-min flotation, a small portion of solution was drained by a pipette, cover glasses removed gently, and examined material was placed on a slide glass.

For the quantitative test and statistical analyses in each of the applied methods, tapeworm eggs were counted for determination of fecal egg count (FEC). The number of found eggs was calculated on the whole surface of the glass slide (flotation and modified sedimentation-flotation techniques) or Petri dish (sedimentation). In the McMaster technique, eggs were counted within the engraved area of both chambers.

\section{Statistical analysis}

Prevalence values (percentage of animals infected) are shown with $95 \%$ confidence limits ( $95 \% \mathrm{CL}$ ), the latter having been calculated according to Rohlf and Sokal (1995). All data were tested for normality. Method sensitivity $(S)$ was calculated as follows:

$S=\frac{\text { number of positive samples }}{\text { number of all samples }} \times 100 \%$

Sensitivity was calculated within two factors. $S_{1}$ was calculated using intensity of invasion (number of tapeworms) and the results of given methods. $S_{2}$ was calculated using number of tapeworms with gravid proglottids and the result of given methods.

Pearson's correlation coefficient was used to estimate the relationship between $\log _{10}$ intensity of infection and fecal egg count (FEC) and between $\log _{10}$ number of tapeworms with 
gravid segments and FEC. All means are reported \pm standard error of mean (S.E.M) unless other stated. All statistical analyses were conducted using R version 2.12.0 (R Development Core Team, 2010) and MS Excel, 2010. A probability of $<0.05$ was considered significant.

\section{Results}

In total, 36 horses were infected with $A$. perfoliata with overall prevalence of $7.4 \%$ (4.5-11.8). No other tapeworm species were found in examined horses. The invasion intensity of A. perfoliata varied from 3 to 2,069 individuals (mean worm burden $=265 \pm 76.1$ ). Tapeworms with gravid segments were present in 29 horses. The intensity of invasion in relation to tapeworms with gravid segments ranged from 3 to 1,191 tapeworms (mean worm burden with gravid segments $=164$ \pm 54.1 ). Tapeworms with gravid segments constituted $62 \%$ of all isolated individuals (Table 1). The detection of A. perfoliata invasion varied within applied coproscopic techniques. The number of $A$. perfoliata positive fecal samples was 3.5 times higher using the sedimentation-flotation methods than flotation $\left(S_{1}=58.3\right.$ and $16.7 \%$, respectively). Sedimentation and McMaster's methods found relatively small number of positive samples (three and one positive horses, respectively). The sensitivity $\left(S_{2}\right)$ of the coproscopic techniques during the patent period increased significantly. Sedimentation-flotation and flotation method showed 1.24 times higher sensitivity in patent period rather than in prepatent period of infection. Sensitivity $\left(S_{2}\right)$ increased also for sedimentation and McMaster's methods; however, still these methods were not highly sensitive $\left(S_{2}=10.3\right.$ and $3.4 \%$, respectively) (Table 2 ).

\section{Discussion}

Diagnosing a tapeworm in humans and animals is difficult and fraught with the possibility of error. In addition, there are some differences in the diagnosis of tapeworms from two separate orders, Cyclophyllidea and Pseudophyllidea. This is caused by dissimilarities in the structure of the uterus and various manners of elimination of the invasive eggs. Tapeworms from the Pseudophyllidea order, such as Diphyllobothrium latum, which is common in central Europe, in humans and carnivores, may be diagnosed by classical decantation, flotation methods, or sedimentation-flotation methods using appropriate parameters of flotation fluids (high specific weight). Characteristic eggs (not invasive, with an operculum, morphologically similar to Trematoda eggs) in the mentioned tapeworm species are not stored in the gravid segments but regularly excreted in the feces during the patent period (Raether and Hänel 2003). The sensitivity of the diagnostic methods will depend on the intensity of the invasion and the degree of
Table 1 Results of post-mortem examination and coproscopic methods of $A$.perfoliata positive horses

\begin{tabular}{|c|c|c|c|c|c|c|}
\hline \multirow{2}{*}{$\begin{array}{l}\text { No. of } \\
\text { horse }\end{array}$} & \multicolumn{2}{|c|}{ Post-mortem examination } & \multicolumn{4}{|c|}{ FEC } \\
\hline & $\begin{array}{l}\text { Number of } \\
\text { tapeworms (intensity } \\
\text { of infestation) }\end{array}$ & $\begin{array}{l}\text { Number of } \\
\text { tapeworms } \\
\text { with gravid } \\
\text { proglottids }\end{array}$ & Sed & $\mathrm{McM}$ & $F$ & Sed-F \\
\hline 1 & 98 & 69 & 0 & 0 & 0 & 8 \\
\hline 2 & 35 & 0 & 0 & 0 & 0 & 0 \\
\hline 3 & 112 & 14 & 0 & 0 & 0 & 0 \\
\hline 4 & 43 & 0 & 0 & 0 & 0 & 0 \\
\hline 5 & 165 & 148 & 0 & 0 & 0 & 12 \\
\hline 6 & 38 & 4 & 0 & 0 & 0 & 0 \\
\hline 7 & 67 & 53 & 0 & 0 & 0 & 7 \\
\hline 8 & 32 & 7 & 0 & 0 & 0 & 0 \\
\hline 9 & 9 & 9 & 0 & 0 & 0 & 3 \\
\hline 10 & 12 & 12 & 0 & 0 & 0 & 2 \\
\hline 11 & 43 & 7 & 0 & 0 & 0 & 0 \\
\hline 12 & 27 & 0 & 0 & 0 & 0 & 0 \\
\hline 13 & 145 & 4 & 0 & 0 & 0 & 0 \\
\hline 14 & 66 & 66 & 1 & 0 & 0 & 17 \\
\hline 15 & 137 & 73 & 0 & 0 & 1 & 15 \\
\hline 16 & 78 & 57 & 0 & 0 & 0 & 9 \\
\hline 17 & 3 & 0 & 0 & 0 & 0 & 0 \\
\hline 18 & 912 & 691 & 0 & 0 & 2 & 24 \\
\hline 19 & 524 & 486 & 0 & 0 & 0 & 18 \\
\hline 20 & 747 & 633 & 2 & 0 & 2 & 33 \\
\hline 21 & 248 & 32 & 0 & 0 & 0 & 0 \\
\hline 22 & 595 & 43 & 0 & 0 & 0 & 5 \\
\hline 23 & 254 & 32 & 0 & 0 & 0 & 4 \\
\hline 24 & 65 & 53 & 0 & 0 & 0 & 15 \\
\hline 25 & 2,069 & 1,172 & 0 & 0 & 2 & 31 \\
\hline 26 & 1,448 & 1,191 & 2 & 1 & 4 & 85 \\
\hline 27 & 22 & 0 & 0 & 0 & 0 & 0 \\
\hline 28 & 162 & 37 & 0 & 0 & 0 & 9 \\
\hline 29 & 38 & 0 & 0 & 0 & 0 & 0 \\
\hline 30 & 1,076 & 830 & 0 & 0 & 0 & 19 \\
\hline 31 & 52 & 48 & 0 & 0 & 0 & 7 \\
\hline 32 & 65 & 65 & 0 & 0 & 0 & 25 \\
\hline 33 & 68 & 68 & 0 & 0 & 3 & 29 \\
\hline 34 & 48 & 15 & 0 & 0 & 0 & 0 \\
\hline 35 & 9 & 3 & 0 & 0 & 0 & 0 \\
\hline 36 & 43 & 0 & 0 & 0 & 0 & 0 \\
\hline Total & 36 & 29 & 3 & 1 & 6 & 21 \\
\hline
\end{tabular}

tapeworm maturity (Figs. 1 and 2). Regarding tapeworms from the Cyclophyllidea order, eggs are not regularly excreted outside the uterus but are stored inside, where they mature. After isolation and disintegration of gravid segments (what takes place in the environment), after the expulsion of the 
Table 2 Sensitivity of coproscopic methods used for A. perfoliata diagnosis

\begin{tabular}{|c|c|c|c|c|}
\hline Technique & McM & Sed & $F$ & Sed-F \\
\hline & \multicolumn{4}{|c|}{ Sensitivity } \\
\hline$S_{1}$ & 2.8 & 8.3 & 16.7 & 58.3 \\
\hline \multirow[t]{2}{*}{$S_{2}$} & 3.4 & 10.3 & 20.7 & 72.4 \\
\hline & \multicolumn{4}{|c|}{ Pearson's correlation coefficient } \\
\hline $\begin{array}{l}\text { Intensity (number of both mature and } \\
\text { juvenile stages of } A \text {. perfoliata) }\end{array}$ & 0.40 & 0.44 & 0.64 & 0.69 \\
\hline$P$ value & 0.134 & 0.065 & $<0.0001$ & $<0.0001$ \\
\hline $\begin{array}{l}\text { Number of tapeworms with gravid } \\
\text { segments }\end{array}$ & 0.52 & 0.54 & 0.71 & 0.8 \\
\hline$P$ value & 0.012 & 0.007 & $<0.0001$ & $<0.0001$ \\
\hline
\end{tabular}

hosts, the eggs are dispersed in the feces. This process does not happen often. In some cases, the disintegration of segments occurs in the intestine and then isolated eggs will be present in the feces. In this case, application of sedimentation, flotation, or sedimentation-flotation techniques has a limited usage. Depending on the tapeworm species, only a small part of the eggs will be present in the feces. The remaining eggs will still be found in the uterus, in the gravid segments excreted. Moreover, the segments are not always excreted regularly.

Such an incidence occurs in invasions of Cyclophyllidea tapeworms (family: Taeniidae) in carnivores. In these invasions, the application of these methods is not sufficiently reliable. The coproscopic technique should be additionally extended by macroscopic and microscopic examinations of fecal samples for the existence of segments of tapeworms (Raether and Hänel 2003). The family Anoplocephalidae is an exception inside in the order Cyclophyllidea. Segments of these tapeworms are specifically short what helps to disintegrate and release the eggs (Schuster 1991). Frequently, eggs appear in the course of the invasion of these tapeworms in the

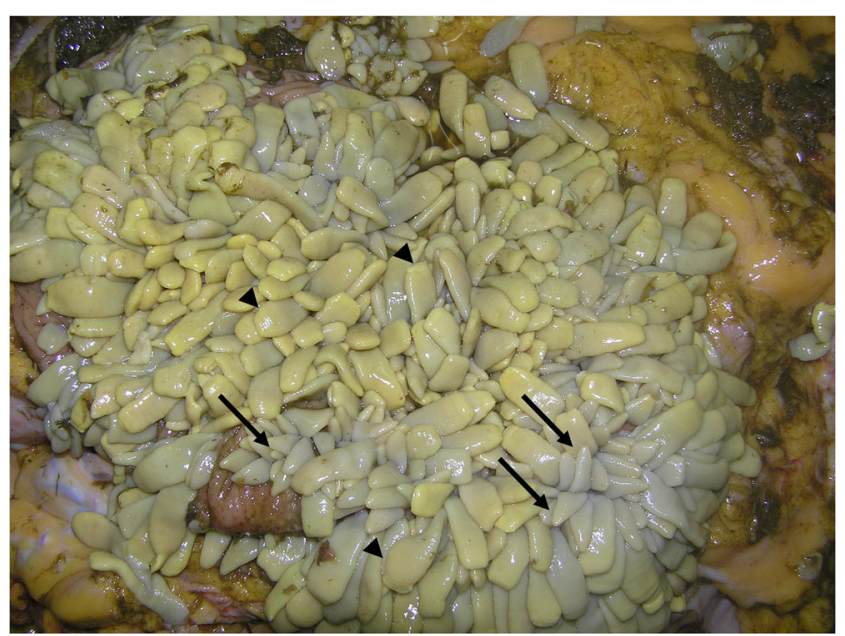

Fig. 1 Beginning of patent period during the invasion of Anoplocephala perfoliata (horse number 25). Immature tapeworms (arrows) and tapeworms with gravid segments (arrow heads)

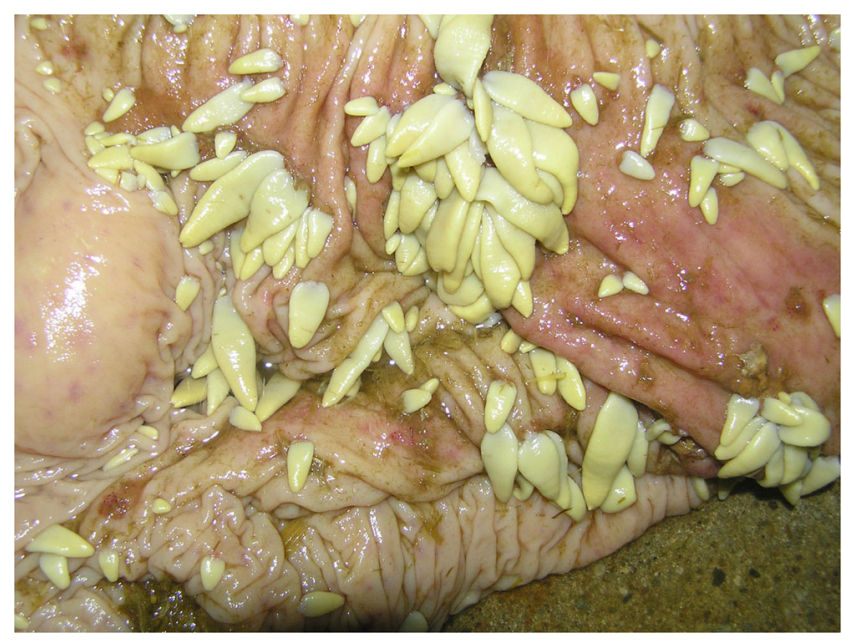

Fig. 2 Prepatent period of invasion (horse number 13). Lance-shapedlike strobila of immature Anoplocephala perfoliata

feces of the infected animals before reaching the defragmentation of the strobila and gravid segment separation. This is particularly evident regarding the $A$. perfoliata tapeworms. A relatively small number of segments and then the damage to the walls between the segments cause eggs to disperse in the intestine of the host before the detachment of the segment. This occurrence probably has a minor significance in tapeworms achieving significant size, such as Moniezia spp. or Anoplocephala magna, where large fragments of strobila are disconnected. A. perfoliata is a specific species of tapeworm, in which, despite belonging to the order Cyclophyllidea, eggs occur regularly in the feces during the patent period (Fig. 3). It is similar with Pseudophyllidea tapeworms, although a different mechanism is at work. Taking that into consideration the diagnostics of the invasion of $A$. perfoliata tapeworms may be applied to the coproscopic method and that effectiveness will be differentiated.

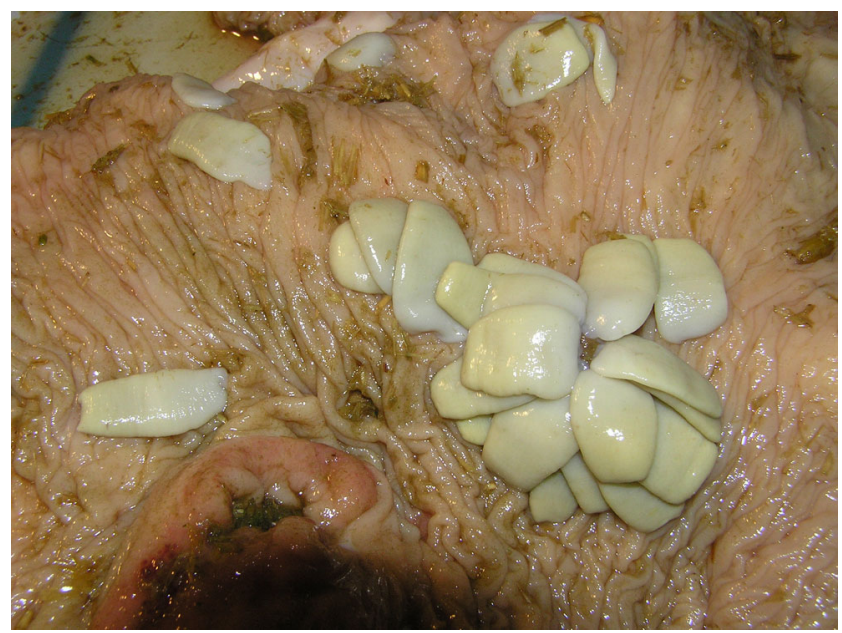

Fig. 3 Invasion in the patent period (horse number 14). All tapeworms with gravid segments 
Despite the progress in parasitology diagnostics and availability of serological and molecular techniques, the routine diagnostics of equine performance test is based on coproscopic examinations (Gundlach et al. 2003; Hearn and Hearn 1995; Skotarek et al. 2010; Williamson et al. 1998). This study compared the effectiveness of basic coproscopic methods. The sedimentation method is rarely used in the study of feces in horses. Sedimentation may be recommended in analysis of equine fecal samples due to the presence of Fasciolla hepatica in horses (Sadzikowski et al. 2009).

Small number of excreted eggs in relation to volume of horse feces makes the classic sedimentation or flotation methods useless. Our findings indicating the sensitivity at a level of $2.8-16.7 \%$ are consistent with the other results which reported the sensitivity at a level of 2-13\% (Hearn and Hearn 1995). Numerous intensive infections demonstrated relatively a small number of eggs. However, the opposite phenomenon was also observed; invasions with a negligible intensity produced a relatively high (allowing for their detection) number of eggs in the feces. Considering the structure of infestations, it was also found that invasions with tapeworms at various maturity stages were undetectable or showed a small number of eggs in feces. It may be assumed that parasites were at an early stage of egg production, which explains a small number of eggs in the feces. However, the invasions attributed only to mature parasites (all tapeworms matured, horses no. 9, 12, 32, and 33) demonstrated a large number of eggs in the feces in relation to the intensity of the invasion. Our results showed that the sensitivity of the sedimentation-flotation methods increases by more than $14 \%$ when we analyzed the feces only from horses in patent stage of invasion. Moreover, the Pearson's correlation coefficient between $\log 10$ number of tapeworms with gravid segments and FEC was higher than $\log 10$ total intensity of infection and FEC.

These relationships also confirmed by others (Gasser et al. 2005; Traversa et al. 2008) may explain varying effectiveness of coproscopic techniques during the invasion of tapeworms in horses. Another important factor that determines the efficacy of the coproscopic techniques is the weight of analyzed samples, which is relatively small ( 2 to $3 \mathrm{~g}$ ) in the McMaster, flotation, and sedimentation techniques. The application of the sedimentation-flotation technique allowing for a marked increase in the mass of the sample and the use of flotation fluids with a high specific gravity considerably increases the detection sensitivity up to $38-42 \%$ (Rehbein et al. 2011; Williamson et al. 1998), $54 \%$ (Meana et al. 1998), and $61 \%$ (Proudman and Edwards 1992). Our findings showed a $58.3 \%$ sensitivity confirmed the results mentioned above. The detection limit for the sedimentation-flotation techniques is 10 tapeworms at the patent invasion stage (Williamson et al. 1998). In the present study, we were able to detect nine matured tapeworms by the sedimentation-flotation method. The infection intensity and the stage of parasite maturity decide on the sensitivity of the sedimentation-flotation methods. Kjaer et al. (2007) provided evidence that the detection of $A$. perfoliata invasion increases to $89 \%$ when the intensity of infection is higher than 20 tapeworms with uterine segments.

Recently, immunological techniques have been introduced for tapeworm diagnosis; the ELISA detects the presence of IgG antibodies in the serum or excretory-secretory antigens in the feces of the infected animals (Höglund et al. 1995; Kania and Reinemeyer 2005; Traversa et al. 2008). These methods also pose a risk for errors because the antigens are present in the serum of horses, 3 weeks after the infection and may persist at detectable levels within 28 days after the parasite elimination. Moreover, their titer and the IgG antibody levels depend on the invasion intensity (Traversa et al. 2008). Therefore, the sensitivity of serological methods is comparable to sedimentation-flotation techniques and ranges from 70-74\% (Rehbein et al. 2002). On the other hand, $97 \%$ sensitivity of PCR-based diagnostics seem to be much more sensitive by the detection of parasite-specific DNA sequences in the feces of animals (Drogemuller et al. 2004; Schnieder 2006). Theoretically, the presence of one tapeworm cell or egg is enough to amplify a selected DNA fragment and read a positive result. Nevertheless, this technique is not always able to detect the invasion during the prepatent period. Method sensitivity depends significantly on the stage of parasite maturity which is associated with the development of parasite invasions. Because of the seasonality of infection, the maturity may peak at different times in central European climate conditions (Tomczuk 2012). Thus, the variability of effectiveness should be taken into account when the examination performed by the same technique is carried out in different seasons. Therefore, the decisions concerning antiparasitics treatment should include not only the results of examination but also the knowledge of invasion conditions and observations of nonspecific clinical symptoms.

To sum up, it may be stressed that tapeworm invasion depends on several specific factors and the sensitivity of routine coproscopic methods is inadequate. The effective detection of tapeworm infection compared to serological techniques is possible when the sedimentation-flotation methods are used.

Open Access This article is distributed under the terms of the Creative Commons Attribution License which permits any use, distribution, and reproduction in any medium, provided the original author(s) and the source are credited.

\section{References}

Barclay WP, Phillips TN, Foerner JJ (1982) Intussusception associated with Anoplocephala perfoliata infection in five horses. J Am Vet Med Assoc 180:752-753 
De Almeida JC, Augusto Mde M, Da Silva TG, De Toledo PS, De Souza DF, Antunes J, Molento MB (2008) Quantitative prevalence of Anoplocephala sp. and egg shedding consistency in horses. Rev Bras Parasitol Vet 17:158-162

Deplazes P, Eckert J, Von Samson-Himmelstjerna G, Zahner H (2013) Lehrbuch der Parasitologie für Die Tiermedizin. Enke Verlag, Stuttgart

Drogemuller M, Beelitzb P, Pfisterb K, Schnieder T, Von SamsonHimmelstjernaa G (2004) Amplification of ribosomal DNA of Anoplocephalidae: Anoplocephala perfoliata diagnosis by PCR as a possible alternative to coprological methods. Vet Parasitol 124:205-215

Gasser RB, Williamson RMC, Beveridge I (2005) Anoplocephala perfoliata of horses - significant scope for further research, improved diagnosis and control. Parasitology 131:1-13

Gawor J (1995) The prevalence and abundance of internal parasites in working horses autopsied in Poland. Vet Parasitol 58:99-108

Gundlach JL, Sadzikowski AB, Tomczuk K (2003) Diagnosis of tapeworm infestation in horses. Medycyna Wet 59:532-535

Gundlach JL, Sadzikowski AB, Tomczuk K, Studzińska MB (2004) Parasites of the alimentary tract of horses from the Lublin district in the light of coproscopic and gross anatomopatological examinations. Medycyna Wet 60:1089-1092

Hearn FPD, Hearn EE (1995) A simple diagnostic technique to better determine the prevalence of tapeworms. J Equine Vet Sci 15:96-98

Hinney B, Wirtherle NC, Kyule M, Miethe N, Zessin KH, Clausen PH (2011) Prevalence of helminths in horses in the state of Brandenburg, Germany. Parasitol Res 108:1083-1091

Höglund J, Ljungström BL, Nilsson O, Uggla A (1995) Enzyme-linked immunosorbent assay (ELISA) for the detection of antibodies to Anoplocephala perfoliata in horse sera. Vet Parasitol 59:97-106

Kania SA, Reinemeyer CR (2005) Anoplocephala perfoliata coproantigen detection: a preliminary study. Vet Parasitol 127:115-119

Kjaer LN, Lungholt MM, Nielsen MK, Olsen SN, Maddox-Hyttel C (2007) Interpretation of serum antibody response to Anoplocephala perfoliata in relation to parasite burden and faecal egg count. Equine Vet J 39:529-533

Kornaś S, Skalska M, Nowosad B, Gawor J, Labaziewicz I, Babiuch A (2007) Occurrence of tapeworm, roundworm and botfly larvae in horses from southern Poland. Medycyna Wet 63:1373-1376

Kornaś S, Cabaret J, Skalska M, Nowosad B (2010) Horse infection with intestinal helminths in relation to age, sex, access to grass and farm system. Vet Parasitol 15:285-291. doi:10.1016/j.vetpar.2010.09.007

Meana A, Luzon M, Corchero J, Gómez-Bautista M (1998) Reliability of coprological diagnosis of Anoplocephala perfoliata infection. Vet Parasitol 74:79-83

Michela C, Gianluca F, Rondolottp A, Pellegrini D, Tambinp P, Ming K, Traversa D, Perruccp S (2009) Infestazione da anoplocefalidi (Cestoda, Cyclophyllidea) in cavalliallevati in Toscana. Ippologia 20:33-38

Nilsson O, Ljungström BL, Höglund J, Lundquist H, Uggla A (1995) Anoplocephala perfoliata in horses in Sweden: prevalence, infection levels and intestinal lesions. Acta Vet Scand 36:319-328

Pavone S, Veronesi F, Genchi C, Fioretti DP, Brianti E, Mandara MT (2011) Pathological changes caused by Anoplocephala perfoliata in the mucosa/submucosa and in the enteric nervous system of equine ileocecal junction. Vet Parasitol 176:43-52

Proudman CJ, Edwards GB (1992) Validation of a centrifugation/ flotation technique for the diagnosis of equine cestodiasis. Vet Rec 131:71-72
Proudman CJ, Holdstock NB (2000) Investigation of an outbreak of tapeworm-associated colic in a training yard. Equine Vet J Suppl $32: 37-41$

Proudman CJ, Trees AJ (1999) Tapeworms as a cause of intestinal disease in horses. Parasitol Today 15:156-159

Raether W, Hänel H (2003) Epidemiology, clinical manifestations and diagnosis of zoonotic cestode infections: an update. Parasitol Res 91:412-438

Rehbein S, Visser M, Winter R (2002) Koproskopische untersuchungen bei pferden in Deutschland und Österreich. Pferdeheilkunde 18: 439-442

Rehbein S, Lindner T, Visser M, Winter R (2011) Evaluation of a double centrifugation technique for the detection of Anoplocephala eggs in horse faeces. J Helminthol 85:409-414

Rehbein S, Visser M, Winter R (2013) Prevalence, intensity and seasonality of gastrointestinal parasites in abattoir horses in Germany. Parasitol Res 112:407-413. doi:10.1007/s00436-012-3150-0

Rohlf F, Sokal RR (1995) Statistical tables. WH Freeman and Company, San Francisco

Ryu SH, Bak UB, Kim JG, Yoon HJ, Seo HS, Kim JT, Park JY, Lee CW (2001) Cecal rupture by Anoplocephala perfoliata infection in a thoroughbred horse in Seoul Race Park, South Korea. J Vet Scie (Suwon-si, Korea) 2:189-193

Sadzikowski AB, Studzińska MB, Tomczuk K, Demkowska M (2009) Fasciola hepatica invasion in horses from central and eastern Poland. Medycyna Wet 65:707-710

Sangioni LA, Vogel FSF, Da Rosa VA, Camillo G, Araújo L, Montemezzo E, Cezar AS (2009) Epidemiologia da infecção por anoplocefalídeos em eqüinos do Jockey Club de Santa Maria. Sem Cienc Agr 30:163-170

Schnieder T (2006) Veterinärmedizinische parasitologie. Parey Verlag, Stuttgart

Schuster R (1991) Morphometric analysis of an Anoplocephala perfoliata population. Angewandte Parasitol 32:105-111

Skotarek SL, Colwell DD, Goater CP (2010) Evaluation of diagnostic techniques for Anoplocephala perfoliata in horses from Alberta, Canada. Vet Parasitol 172:249-255

Ślivińska K, Gawor J, Jaworski Z (2009) Gastro-intestinal parasites in yearlings of wild Polish primitive horses from the Popielno Forest Reserve, Poland. Helminthologia 46:9-13

Slocombe D (2006) A modified critical test and its use in two dose titration trials to assess efficacy of praziquantel for Anoplocephala perfoliata in equids. Vet Parasitol 136:127-135

Tomczuk K (2012) The characteristic of the Anoplocephala perfoliata invasion in horses in relation to molecular and proteomic aspects of invasion. WUP, Lublin

Traversa D, Fichi G, Campigli M, Rondolotti A, Iorio R, Proudman CJ, Pellegrini D, Perrucci S (2008) A comparison of coprological, serological and molecular methods for the diagnosis of horse infection with Anoplocephala perfoliata (Cestoda, Cyclophyllidea). Vet Parasitol 152:271-277

Trotz-Williams L, Physick-Sheard P, McFarlane H, Pearl DL, Martin SW, Peregrine AS (2008) Occurrence of Anoplocephala perfoliata infection in horses in Ontario, Canada and associations with colic and management practices. Vet Parasitol 153:73-84

Williamson RM, Beveridge I, Gasser RB (1998) Coprological methods for the diagnosis of Anoplocephala perfoliata infection of the horse. Aust Vet J 76:618-621 